\title{
ESTUDOS MÉTRICOS DA INFORMAÇÃO: primeiras aproximações
}

\author{
METRIC STUDIES OF INFORMATION: first approaches \\ Daisy Pires Noronha - daisynor@usp.br \\ Professora Doutora. Departamento de Biblioteconomia e Documentaçào. Escola de \\ Comunicações e Artes da USP. Núcleo de Produçào Científica. São Paulo, SP, Brasil. \\ João de Melo Maricato - jmaricato@sorocaba.unesp.br \\ Professor do Curso de Biblioteconomia das Faculdades IMAPES. Mestrando do \\ Programa de Pós-Graduaçào em Ciência da Informaçào da ECA/USP. Bibliotecário na \\ UNESP/Campus Sorocaba.
}

\begin{abstract}
Resumo
Apresentam-se alguns conceitos e considerações fundamentais dos estudos métricos da informação e os principais métodos e técnicas utilizadas, como a bibliometria, cienciometria, informetria, webmetria, patentometria e biblioteconometria. Discute-se o ciclo de comunicação científica, destacando-se os principais indicadores de input (insumo) e output (produto), assim como, a importância da publicação dos resultados da pesquisa científica e do processo de avaliação pelos pares. Comentam-se algumas características e aplicações das leis bibliométricas e de outros recursos utilizados nos estudos métricos da informação.
\end{abstract}

Palavras-chave: Técnicas bibliométricas. Comunicação Científica. Leis bibliometricas. Indicadores de input. Indicadores de output.

\section{INTRODUÇÃO}

O desenvolvimento da pesquisa em C\&T e a expansão de universidades e centros de pesquisa tiveram grande impulso, internacionalmente, no período pós-guerras até meados dos anos 60 do século passado. No Brasil, esse quadro desenvolve-se a partir da década de 70, com a criação dos cursos de pós-graduação strictu sensu que contribuíram para o crescente desenvolvimento das pesquisas nas diferentes áreas do conhecimento, com pauta bastante variada, além de responder pela formação de pessoal altamente qualificado. Embora exerça um papel preponderante no aumento do número de pesquisas nas diferentes áreas, os cursos de pós-graduação contam também com a parceria de outros fatores nesse processo. Assim, segundo Miranda e Barreto(1999/2000), o aumento das investigações no país deu-se com a implantação dos grandes sistemas de informação nas áreas da saúde (Bireme), agrícola (EMBRAPA), engenharia, a partir dos anos 50, que "criaram ambiente adequado para a problematização das questões que motivaram as pesquisas e criaram a demanda para a formação de uma massa crítica" (p.279). Para esses autores, a criação do IBBD e a organização do COMUT, também foram decisivos para esse processo. $\mathrm{Na}$ área da Ciência da Informação, atualmente, os 9 Programas de Pós-Graduação (níveis mestrado e doutorado) respondem pela formação e titulação de profissionais da informação e pela 
maior parte da produção científica gerada na área. A criação da ANCIB (Associação Nacional de Pesquisa e Pós-Graduação em Ciência da Informação e Biblioteconomia), principal sociedade científica da área, no final da década de 80 , constitui um grande passo para dar visibilidade das pesquisas produzidas nos programas de pós-graduação, principalmente pela oportunidade que oferece aos docentes, alunos e pesquisadores da área, nos Encontros anuais realizados.

É reconhecido o fato de a pesquisa científica ser condição básica para a evolução do ser humano, provocando e ampliando permanentemente a evolução do conhecimento. Há que se considerar, no entanto, que não basta apenas "pesquisar", para se ter um novo domínio, um novo conhecimento - é fundamental a sua validação, o seu aceite pela comunidade científica. Assim, para que atue na ampliação das fronteiras do conhecimento há necessidade que os resultados obtidos nas investigações realizadas sejam amplamente divulgados. Segundo Targino (1999/2000) "a ciência faz da pesquisa científica seu instrumento-mor e da comunicação científica seu elemento básico, de tal forma que a pesquisa científica e a divulgação de seus resultados são atividades inseparáveis"(p.347). Por meio da apresentação e discussão de conceitos, métodos e técnicas, este texto pretende ser uma contribuição ao desenvolvimento dos estudos métricos da ciência no país. Para isso, são apresentados, com finalidades didáticas, conceitos relativos às medidas da ciência (input e output), os principais métodos e técnicas utilizados na análise e avaliação da ciência, suas semelhanças e diferenças e as principais leis bibliométricas

\section{MEDIDAS DA CIÊNCIA}

Como a ciência passou a ser vista como determinante para o desenvolvimento econômico e social de qualquer nação, nota-se, a partir da década de 60 , um crescente interesse em coletar informações sobre todo o processo das atividades de C\&T para que estas sejam planejadas, monitoradas e avaliadas.

Segundo Mugnaini et alii.(2006, p.316), "para se entender a evolução da ciência, como forma de expressão do conhecimento humano produzido são utilizadas técnicas de medição", aplicadas em estudos métricos que são realizados para estabelecimento ou fortalecimento de indicadores que permitem traçar um perfil do mundo científico, tanto em âmbito nacional como internacional.

No campo da politica científica e tecnológica, importar esses indicadores de países desenvolvidos, para qualificar o conhecimento produzido nos países de menor desenvolvimento, tem criado uma série de polêmicas. Na realidade, essa rotina - como, por exemplo, o uso indiscriminado de bases de dados como as desenvolvidas pelo ISI pode criar mais problemas que soluções. A necessidade de se estabelecer indicadores específicos da ciência gerada no Brasil, independentes dos preconizados nos países de ponta, tem levado os pesquisadores à realização de estudos métricos de diferentes áreas, a partir de diferentes fontes de dados criados em âmbito nacional (dentre as novas bases de dados existentes, merece destaque o projeto SCIELO). Essas medidas têm sido aplicadas em diversos campos e áreas de conhecimento, sendo muito utilizadas como ferramentas para tomada de decisão e formulação de políticas públicas ou institucionais. 
A literatura sobre o assunto apresenta algumas oscilações na sua trajetória de produtividade. Na década de 70 verifica-se um ápice de produção, com a introdução de estudos bibliométricos em trabalhos acadêmicos, temática que sofre uma queda sensível ao longo dos anos 80 (ARAUJO, 2006). A partir da metade dos anos 90, verifica-se um crescer contínuo na produção de estudos envolvendo metodologias quantitivas graças, principalmente, aos novos recursos tecnológicos disponíveis, que facilitaram não só a coleta dos dados nas fontes de origem, como o tratamento dos mesmos, segundo as variáveis estudadas, pelos softwares específicos, que cada vez mais auxiliam a "trabalhosa" tarefa na lida com grande quantidade de números.

Com esse panorama, os estudos bibliométricos vêm se tornando cada vez mais atraentes. E, com o crescimento do interesse por esses tipos de estudos, surgem novas técnicas e métodos, como sub-campos da bibliometria, denominados de cienciometria ou cientometria, informetria, bibliotecometria e, mais recentemente, webmetria, patentometria, que se assemelham por serem métodos quantitativos, mas que se diferenciam quanto ao objeto de estudo. O importante, segundo Lima et alii. (2007), "quando se usam as ferramentas bibliométricas [...] é reconhecer os limites das mesmas para os objetios propostos."

Quaisquer que sejam os métodos empregados nos estudos métricos da ciência, há que se considerar um conjunto de variáveis componentes do processo das atividades científicas, que podem e devem ser medidas, para que as investigações realizadas atinjam resultados positivos.

Assim, no processo da geração do conhecimento científico, atualmente facilitado pelos recursos tecnológicos disponíveis, podem-se considerar, de forma bem generalizada, dois grandes momentos na sua avaliação, que caracterizam os indicadores de Input (insumo) e Output (produto) (Figura 1). Esses indicadores, assim como suas relações e importância para os estudos quantitativos da ciência, são tratados por autores como Spinak (1998) que faz analogia da atividade científica com as de uma empresa, com insumos e resultados. Assim, a medição dessas categorias - insumos (Input) e resultados (Output) - são as bases dos indicadores científicos. Para Población e Oliveira (2006, p.68) "INPUT é uma combinação dos fatores que viabilizam a produção de determinada quantidade de bens e serviços (OUTPUT)". 
Figura 1 - Fluxo da comunicação científica

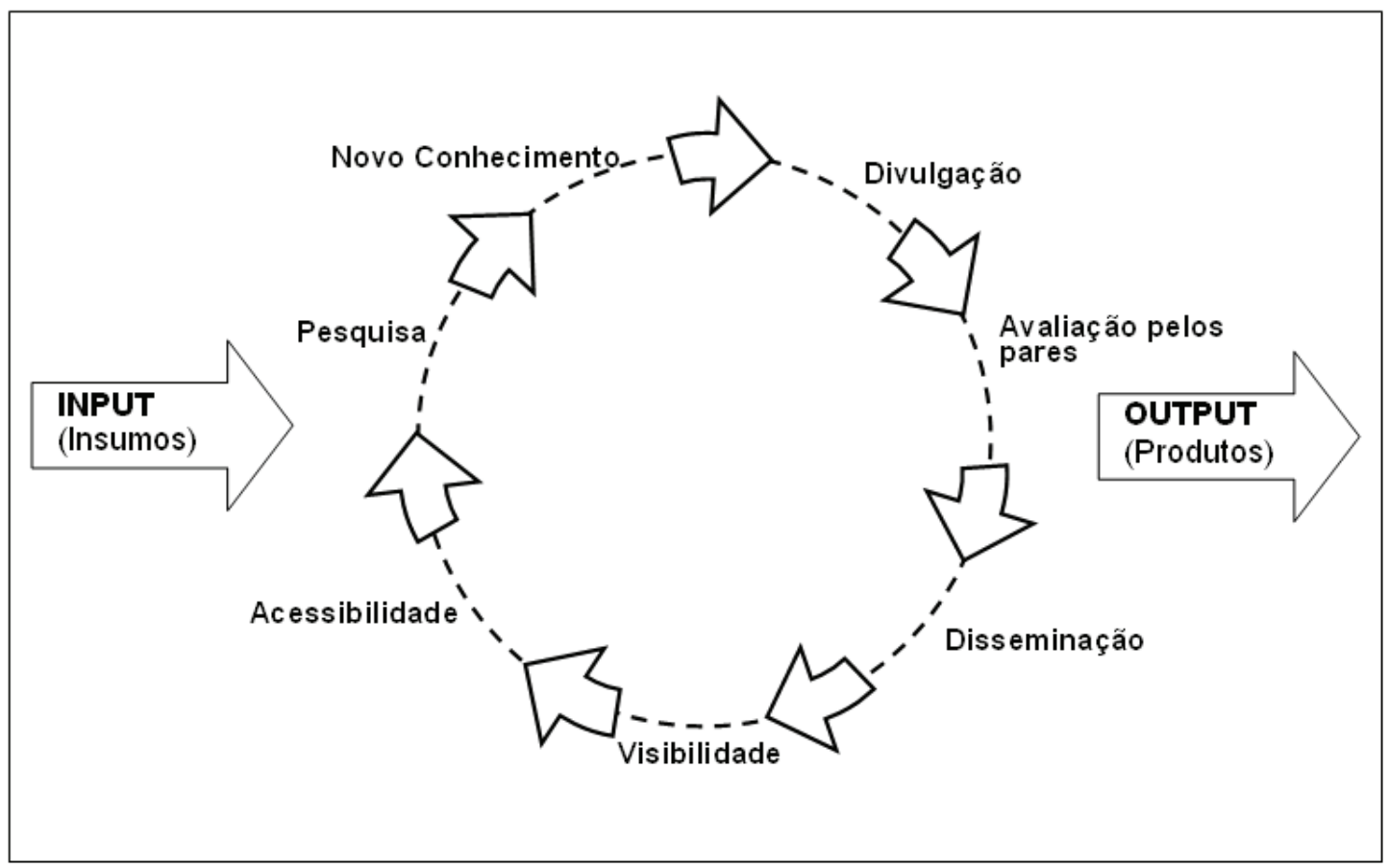

Como indicadores de input há que se considerar a importância dos insumos necessários ao fortalecimento da comunidade científica de pesquisadores e as condições encontradas para a efetivação de suas investigações. Por outro lado, como indicadores de output, têm-se as medidas dos produtos, isto é, a validação do conhecimento gerado, comprovada com a aceitação pelos pares (disseminação) e pela sociedade (divulgação). Nesta etapa devem-se considerar, ainda, os veículos adequados para a disseminação e divulgação das pesquisas e os recursos que garantam sua ampla visibilidade e formas de acessibilidade.

Segundo Macias-Chapula (1998), o foco das avaliações, por muito tempo, permaneceu voltado para a medida dos insumos (verbas, pessoal) e, posteriormente, há crescente interesse pela análise dos indicadores de resultados (produtos). Como somente as informações de insumos (input) não retratam, de modo satisfatório, a dinâmica e as características da atividade científica, os formuladores de políticas públicas passaram a demandar indicadores de resultados (output) que, de acordo com Spinak (1998), são a segunda metade da tarefa, que apresenta, por sua vez, um maior nível de complexidade.

\subsection{Medidas de Input e Output}

O processo que se inicia no planejamento da pesquisa científica e vai até a criação de um novo conhecimento envolve uma série de quesitos condicionados a diversos fatores que merecem ser considerados nas medidas de input e de output, demonstrados na Figura 2. No fluxo da comunicação científica (Figura 1), pode-se perceber que, assim como os indicadores de output estão diretamente relacionados e, até certo ponto são condicionados pelos inputs, nota-se que os mesmos outputs também podem estar 
relacionados e condicionam os inputs. Os grupos de pesquisa, departamentos e as universidades com melhores inputs certamente conseguirão melhores outputs, que por sua vez serão recompensados com maiores recursos financeiros e materiais (inputs) e atrairão melhores recursos humanos, ampliando ainda mais os resultados de output. Trata-se de um círculo (virtuoso ou vicioso) que tem seus prós e contras. Ao mesmo tempo que os núcleos de excelência em determinadas áreas do conhecimento produzem mais porque são mais contemplados pelas agências de fomento, os grupos menores ou recém constituidos não são favorecidos, dada a baixa capacidade de produção, em consequência da precariedade dos insumos.

Figura 2 - Fatores considerados nas medidas de Input (insumos) e Output (produto)

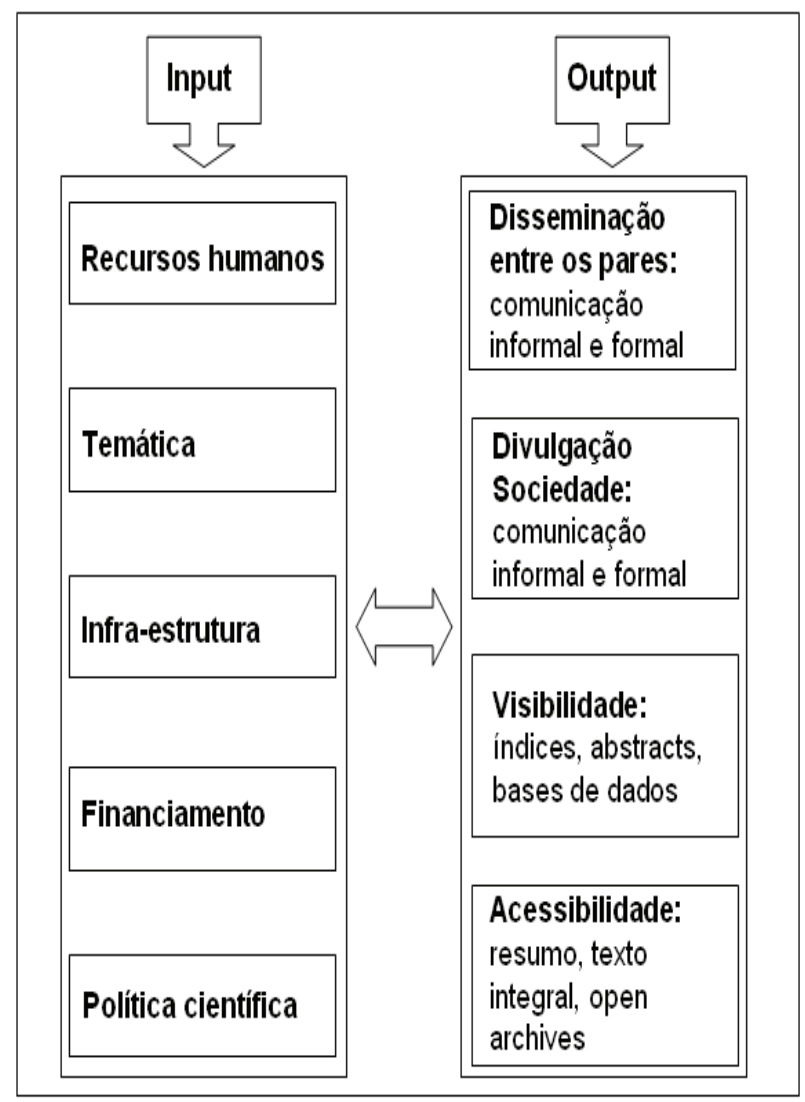

\subsubsection{Medidas de Input}

A importância dos inputs no processo de geração de novos conhecimentos é evidente. Os inputs estão intimanente relacionados aos outputs, podendo influenciar a qualidade e a quantidade dos produtos resultantes da atividade científica. Neste contexto, (DAHLING, 1962 apud MEADOWS, 1999) afirma que a maioria dos estudos demonstra que, no plano institucional, há um conjunto de fatores que se correlacionam com a produtividade e qualidade dos outputs.

Os pesquisadores e cientistas, para desfrutarem de divulgação ampla de seus trabalhos, "carecem de condições mínimas [...] que incluem facilidade de acesso à informação, 
infra-estrutura adequada, possibilidade de comunicaçào com os pares em caráter permanente..." (TARGINO, 1999/2000, p.347).

Dessa forma, todo o cenário construído para o desenvolvimento da pesquisa tem sua parcela de contribuição no produto final, ou, em outras palavras, todo produto gerado nas investigações realizadas (indicadores de output) sofrem a influência das condições básicas de sua geração (indicadores de input). Segundo Población e Oliveira (2006, p.75), "com a crescente melhoria dos indicadores de input certamente ocorrerão mudanças nos demais indicadores".

Como indicadores de input, a pesquisa realizada deve ter o respaldo de:

a) Recursos Humanos - vinculação dos recursos humanos em instituições e sociedades científicas; perfil dos pesquisadores (formação, titulação, idade, áreas de atuação) e colaboradores das equipes de trabalho.

b) Temática - identificação dos temas dos estudos realizados e a integração com as linhas de pesquisa onde se encontram engajados os pesquisadores.

c) Infra-estrutura - condições imprescindíveis para o bom andamento dos trabalhos, com apoio de recursos tecnológicos e informacionais, representados pelos equipamentos, bibliotecas, laboratórios.

d) Financiamento - obtenção de recursos nas agências de fomento, tanto na etapa de desenvolvimento da pesquisa como na divulgação de seus resultados.

e) Política científica - identificação das prioridades expressas nos planos institucional e governamental para projeção nacional e internacional.

\subsubsection{Medidas de Output}

Como indicadores de output são consideradas todas as fases pelas quais o produto gerado passa até ser cosumido por um novo produtor: a disseminação, divulgação, visibilidade e acessibilidade dos produtos gerados. A disseminação e divulgação da produção gerada por uma comunidade científica, para os pares e a sociedade, podem ser feitas nos processos formal e informal de comunicação.

A disseminação das pesquisas entre os pares pode ser feita informalmente, por meio de recursos destituídos de formalismos, como os contatos pessoais, a participação em eventos e em "colégios invisíveis" (atualmente "colégios virtuais"), entre outros meios, e formalmente, por diversos meios da comnunicação escrita. Para Targino (1999/2000, p .353) "a disseminação através de canais informais precede a finalização do projeto de pesquisa e até mesmo o início de sua execução, pois há propensão para se abandonar um projeto quando os pares não demonstram interesse". A autora aponta ainda outro instrumento para divulgar os resultados parciais da pesquisa, por meio dos denominados pré-edições (preprints, prepapers), versões provisórias, cartas ao editor (letters), configurando a comunicação científica semiformal.

A comunicação formal do produto gerado se dá pelos diversos meios de comunicação escrita, com destaque para a publicação de artigos de periódicos e livros, editados tanto no formato impresso como eletrônicas. Toda produção científica formal, quando submetida à publicação, é validada pelos pares, constituídos por membros da comunidade científica, especialistas no tema desenvolvido pelo pesquisador. O processo de avaliação por pares é lento, ocasionando um atraso na divulgação das pesquisas, 
podendo levar "meses ou anos" para que o trabalho seja publicado (CASTRO, 2006). Para Szklo (2006) a avaliação pelos pares é tida como "um sistema imperfeito, com confiabilidade abaixo do ideal e validade duvidosa", mas, mesmo assim, é ainda o principal processo de seleção de artigos para publicação. Esse autor aponta as dificuldades deste julgamento e descreve algumas armadilhas comuns que devem ser evitadas antes e após a publicação de um artigo. A divulgação formal dos resultados de pesquisa, tanto à comunidade científica como à sociedade em geral, tem um longo caminho a percorrer, motivo pelo qual, "os cientistas vêm dando cada vez mais atenção aos elementos informais" (TARGINO, 1999/2000, p.199).

Uma vez finalizada e editada a pesquisa, os interesses voltam-se para os processos de tornar o conhecimento mais visível e facilitar seu acesso. A ampla visibilidade e os recursos de acessibilidade constituem-se na meta final do processo de comunicação dos resultados das pesquisas. Assim, os serviços de informação têm papel de destaque neste processo, com a criação e manutenção das bases de dados bibliográficas especializadas que tornam possível os trabalhos de pesquisas conhecidos em todas as instâncias. Além disso, a disponibilização do texto completo dos documentos, e os novos recursos de acesso livre (open access) propiciam a eqüidade do acesso à informação, tornando real o direito à informação a todos os cidadãos.

\section{ESTUDOS MÉTRICOS DA INFORMAÇÃO}

Atualmente, os principais métodos e técnicas de avaliação quantitativa da ciência são utilizados nos chamados estudos métricos da informação, com diversas abordagens teórico-metodológicas e diferentes denominações em função de seus objetivos e objetos de estudo.

Os estudos métricos da ciência retratam tanto a avaliação dos insumos como, e principalmente, a produção gerada pela comunidade científica de determinada área, nos diferentes formatos de divulgação. Por esses trabalhos podem-se identificar os indicadores das tendência de pesquisas além de os mesmos "apontarem fragilidades teóricas e metodológicas dessa produção, contribuindo, assim, para ultrapassá-las" (GOMES, 2006, p.4).

Estudos dessa natureza, com enfoque tanto na avaliação dos insumos como dos produtos gerados, apresentam abordagens bastante diferenciadas e podem ser analisados em macro, meso ou micro escalas. Dessa forma, poderão ser estudados aspectos sobre a orientação, a dinâmica e a participação da C\&T em escala internacional (através da comparação entre dois ou mais países), nacional (entre dois ou mais estados), local (entre instituições de uma mesma cidade ou região). Cada uma dessas categorias de análise pode ser subdividida e aprofundada, surgindo novas variáveis e abordagens, por campo de atuação (linhas de pesquisa), por pesquisadores (formação, titulação), por colaboração (trabalhos em co-autoria, sociabilidade entre os autores), assuntos, tipos documentais (periódicos, teses, dissertações, eventos, etc), instituições (universidades, centros de pesquisa, empresas), departamentos, cursos, disciplinas, etc. Sem dúvida, existe uma riqueza de detalhes da produção do conhecimento que pode e merece ser descortinada. 
A evolução dos estudos teóricos neste campo, de extrema importância para a interpretação dos dados coletados, das metodologias e das tecnologias de informação e comunicação, ampliou o universo dos estudos métricos e, sobretudo, proporcionou o surgimento de novas abordagens e das variáveis possíveis de serem analisadas.

O interesse pelos estudos métricos, inicialmente voltado à análise de documentos (bibliometria), propiciou o aparecimento de sub-campos de atuação voltados a diferentes objetos de estudo, que são pontos de partida e referências centrais no desenvolvimento de estudos de áreas, disciplinas (cienciometria), de palavras/conteúdos (informetria), de bibliotecas (bibliotecometria), de páginas da web (webmetria), de patentes (patentometria). Essa diversificação de interesses é decorrente, principalmente, dos recursos tecnológicos disponíveis, indispensáveis a esses tipos de estudos. Todos se referem a medidas quantitativas, tendo como diferencial os objetos de estudo, suas variáveis, seus métodos e objetivos (MACIAS-CHAPULA, 1998).

Os estudos métricos da informação, sobretudo os estudos baseados na bibliometria e na cienciometria, atuam em diferentes áreas e com temas relativamente bem definidos e aceitos pela comunidade. Alguns dos principais indicadores extraídos desses estudos podem ser apresentados de modo genérico, incluindo:

- evolução quantitativa e qualitativa da literatura;

- obsolescência da informação e dos paradigmas científicos

- dinâmica e estrutura da comunicação científica (principalmente formal)

- características e funções de diversos tipos documentais (literatura branca e cinzenta)

- ranking de publicações, autores, instituições, países, etc.

- estudos de citação, fator de impacto.

- relações interdisciplinares, intradisciplinares e multidisciplinares na ciência

- estudos de colaboração científica (principalmente baseados em co-autoria)

- comportamentos de uso e crescimento do acervo em bibliotecas

- evolução de disciplinas, sub-disciplinas e novos conceitos

- características de freqüência de ocorrência de palavras em textos

O Quadro a seguir mostra os métodos e técnicas bibliométricos, sendo que, dentre eles, os mais difundidos e com maturidade fortemente consolidada, estão a bibliometria e a cienciometria. 
Quadro - Métodos e Técnicas Bibliométricas

\begin{tabular}{|c|c|c|}
\hline Técnica & Finalidade & Objetos de estudo \\
\hline BIBLIOMETRIA & $\begin{array}{l}\text { Produção e uso de documentos } \\
\text { Organização de serviços bibliográficos. }\end{array}$ & $\begin{array}{l}\text { Documentos (livros, } \\
\text { artigos, teses...), autores, } \\
\text { usuários }\end{array}$ \\
\hline CIENCIOMETRIA & $\begin{array}{l}\text { Organização da ciência Fatores que } \\
\text { diferenciam as sub-disciplinas } \\
\text { Identificar domínios de interesse }\end{array}$ & \begin{tabular}{|lr} 
Disciplinas, & campos, \\
áreas, & assuntos \\
específicos & \\
\end{tabular} \\
\hline INFORMETRIA & $\begin{array}{l}\text { Medição de sistemas de informação. } \\
\text { Recuperação da informação } \\
\text { Estudo conteúdos informativos }\end{array}$ & $\begin{array}{l}\text { Palavras, documentos, } \\
\text { bases de dados }\end{array}$ \\
\hline BIBLIOTECOMETRIA & $\begin{array}{l}\text { Organização de bibliotecas } \\
\text { Administração de serviços de bibliotecas }\end{array}$ & Bibliotecas \\
\hline WEBMETRIA & Organização e uso de sites & $\begin{array}{l}\text { Páginas na internet, } \\
\text { hospedeiros }\end{array}$ \\
\hline PATENTOMETRIA & $\begin{array}{l}\text { Conhecer atividades tecnológica e } \\
\text { inovadora de países, áreas e instituições }\end{array}$ & Patentes \\
\hline
\end{tabular}

Fontes: Macias-Chapula (1998) e Sanz Casado (2006)

Alguns autores se aventuram em dividir tais técnicas de modo bastante sistemático e com uma delimitação precisa entre elas. No entanto, a maioria as consideram bastante próximas e inter-relacionadas, pois estão atreladas, principalmente, à medida da informação e conhecimento em sistemas de informação e comunicação.

Para Sengupta (1992), os termos bibliometria, informetria, cienciometria e biblioteconometria, que derivam da fusão do sufixo "metria" com bibliografia, informação, ciência e biblioteca, respectivamente, são análogos ou muito próximos em sua natureza, objetivos e aplicações. A esses termos adicionam-se, mais recentemente, a webmetria, voltada aos estudos dos recursos disponibilizados na web e a patentometria, que, a partir da análise das patentes, mede o grau de tecnologia e inovação de um país ou de um setor da indústria, além de permitir a busca de relações entre o conhecimento científico e sua contribuição ou transformação em conhecimento tecnológico.

Para Tague-Sutcliffe (1992), a Bibliometria estuda os aspectos quantitativos da produção, disseminação e uso da informação registrada, usando seus resultados para elaborar previsões e apoiar tomadas de decisão e a Cienciometria estuda os aspectos quantitativos da ciência enquanto disciplina ou atividade econômica, centrada no estudo de diferentes atividades científicas, sendo importante para o desenvolvimento de políticas científicas. Para o autor, a Informetria vai mais além, estudando todos os processos quantitativos da informação em geral, incorporando, utilizando e ampliando as fronteiras da bibliometria e da cienciometria.

Partindo de visão semelhante à apresentada por Tague-Sutcliffe (1992), a Figura 3 mostra a representação de alguns dos métodos e técnicas aplicáveis aos estudos métricos da informação, onde a bibliometria tem caráter central e integrador, com correlação interdisciplinar com os demais. Por outro lado, cada um dos métodos e 
técnicas possui particularidades e aplicações próprias, tendo como pano de fundo a informetria, como algo muito mais amplo, que abarca e vai além dos métodos, técnicas e abordagens propostas pela cienciometria, patentometria, bibliometria, webmetria, bibliotecometria.

Figura 3 - Relações entre as técnicas e métodos bibliométricos

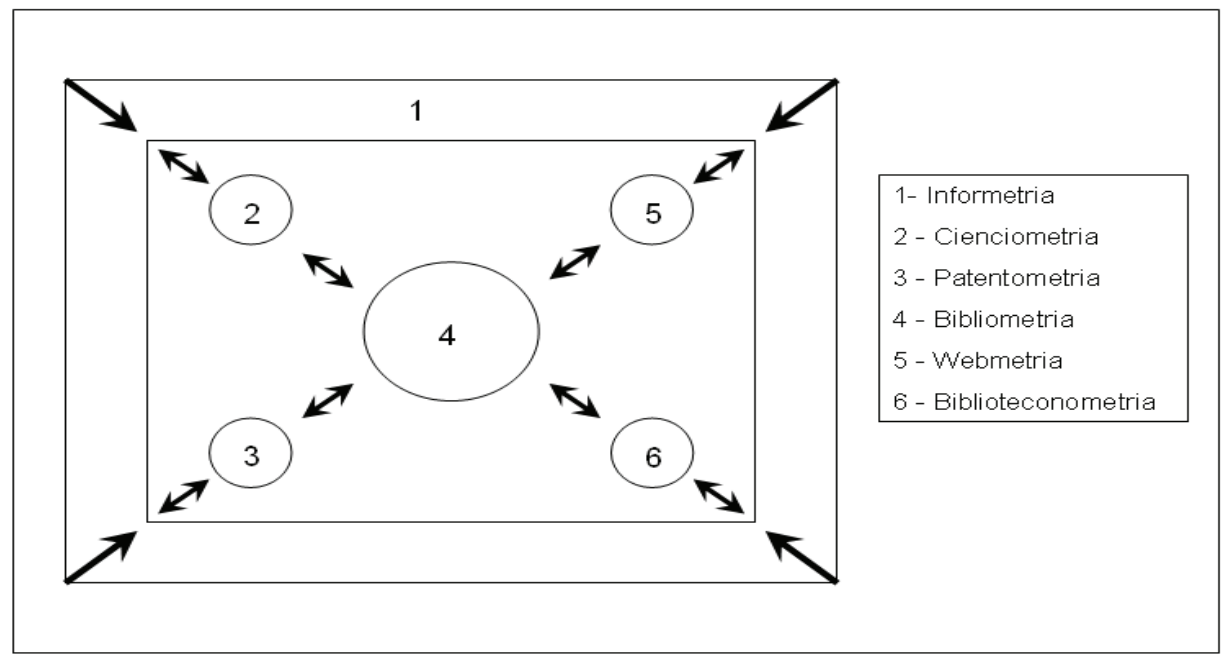

A área de Ciência da Informação vem contribuido fortemente para o desenvolvimento dos estudos métricos da informação, com a participação de especialistas no assunto, em boa parte provenientes dos cursos de pós-graduação. Muitos desses cursos possuem grupos de pesquisa bastante ativos e de fundamental importância para o desenvolvimento de estudos centrados na bibliometria. Dentre eles destacam-se os grupos de pesquisas cadastrados no Diretório do CNPq: Núcleo de Produção Científica (ECA/USP), Grupo Scientia (UFSC), Indicadores de C\&T e Inovação (UFSCar), Comunicação e Divulgação Científica (IBICT/UFF), Comunicação Científica (UnB); Comunicação Científica (UFRGS), Comunicação Científicas em Ciências do Movimento Humano (EDESC), entre outros.

\section{LEIS BIBLIOMÉTRICAS}

Os estudos métricos da ciência são desenvolvidos com a aplicação das chamadas leis bibliométricas, tidas como seus sustentáculos. As primeiras leis empíricas do comportamento da literatura voltaram-se para a medição da produtividade de autores (lei de Lotka, em 1926); para medir a dispersão do conhecimento científico em publicações periódicas (lei de Bradford, de 1934) e como modelo de distribuição de freqüência de palavras de um texto (lei de Zipf, de 1949).

a) lei de Lotka - por esta lei determinou-se que uma grande quantidade de literatura científica é produzida por um pequeno número de autores e um grande número de pequenos produtores se iguala, em produção, ao reduzido número de grandes produtores. Esta lei foi aperfeiçoada por Price (citado por Araújo, 2006) que concluiu que $1 / 3$ da literatura é produzida por menos de $1 / 10$ dos autores mais produtivos (média de 3,5 documentos/autor) e $60 \%$ dos autores produzindo um único documento. 
b) Lei de Bradford - estuda a dispersão da publicação de artigos de periódicos de um assunto em revistas destinadas a outros assuntos, em decorrência do fato de a metade do total de artigos úteis não serem cobertos pelos serviços de indexação e resumos. $\mathrm{O}$ enunciado desta lei mostra que se os periódicos forem dispostos em ordem decrescente de produtividade de artigos de um determinado assunto, pode-se identificar um núcleo de títulos mais particularmente voltados a esse tema e vários grupos ou zonas que incluem o mesmo número de artigos que o núcleo que detém o maior número de títulos. $\mathrm{Na}$ literatura constam diferentes formas de se determinar o núcleo dos títulos mais produtivos, em função das reformulações e aperfeiçoamentos por que passou. Assim, para determinação do core dos títulos produtivos, o total de artigos deve ser somado e divido por três e, na lista decrescente de produtividade dos títulos, aparecem 3 zonas, cada uma contendo 1/3 do total de artigos relevantes (ARAÚJO, 2006). Neste caso, a primeira zona (ou núcleo) contém um pequeno número de periódicos altamente produtivos, a segunda contém um número maior de periódicos menos produtivos e, a terceira, inclui número maior de periódicos com menor produtividade. Sanz Casado (2006) indica que os periódicos podem ser agrupados em apenas 2 zonas de produtividade $-50 \%$ dos títulos mais produtivos correspondem aos da zona 1 (núcleo) e os demais, aos da zona 2. Vickery, citado por Araújo (2006), propõe que o número de zonas pode ser qualquer um e não precisamente três. Além do estudo da dispersão de publicações de um assunto para determinação de "core lists", esta lei é também utilizada em práticas bibliotecárias (estudo de uso de coleção para tomada de decisões administrativas, como aquisição, descartes, encadernação, depósitos, predição da circulação de acervo, planejamento de sistemas e outros).

c) Lei de Zipf - descreve a relação entre palavras num determinado texto e determina que existe correlação entre o número de palavras diferentes e a freqüência de seu uso um pequeno número de palavras é usado muito mais freqüentemente. A partir daí, Zipf formulou o princípio do menor esforço - existe uma economia no uso de palavras. Determina também que as palavras mais usadas indicam o assunto do documento. " $\mathrm{O}$ método foi sendo aperfeiçoado, ainda, principalmente com estudos de freqüência e coocorrência de descritores" (ARAÚJO, 2006, p.17)

Além da aplicação dessas leis bibliométricas, vários estudos bibliométricos têm sido elaborados com base em diferentes recursos, como análise de citação, cujos dados permitem descobrir: elite da pesquisa (autores mais produtivos); frente de pesquisa; fator de impacto dos autores e dos periódicos; tipos de documentos citados; vida média da literatura e obsolescência da literatura citada; sociabilidade dos autores (procedência geográfica e institucional dos autores); entre outros.

\section{CONSIDERAÇÕES}

Os estudos métricos da ciência surgiram pela necessidade de avaliar as atividades inerentes à produção e comunicação científicas. A partir do desenvolvimento de leis empíricas sobre o comportamento da literatura e outros meios de comunicação, vêm se destacando no cenário científico com sua popularização e aperfeiçoamento de técnicas e métodos, graças ao desenvolvimento sempre crescente das tecnologias da informação.

A importância da realização de estudos de medidas da ciência, tanto dos indicadores de insumo como da produção gerada, além de ajudar a refinar procedimentos 
metodológicos específicos, contribui para o estabelecimento de nossos próprios indicadores, à luz de nosso contexto econômico e social. Com isso, pode-se acompanhar o desenvolvimento da C\&T com nossos próprios olhos e não através de janelas extramuros.

\section{REFERÊNCIAS}

ARAUJO, Carlos Alberto. Bibliometria: evolução histórica e questões atuais. Em Questão, Porto Alegre, v.12, n.1, p.11-32, jan./jun. 2006.

CASTRO, Regina C.Figueiredo. Impacto da Internet no fluxo da comunicação científica em saúde. Revista de Saúde Pública, v.40, p.57-63, ago. 2006. Número especial.

GOMES, Maria Yêda Falcão Soares de Figueiras. Tendências atuais da produção científica em Biblioteconomia e Ciência da Informação no Brasil. DataGramaZero: Revista de Ciência da Informação, v.7, n.3, jun. 2006. Disponível em: www.dgz.org.br. Acesso em: 07/08/2007.

LIMA, Ricardo Arcanjo de; VELHO, Lea Maria Leme Strini; FARIA, Leandro Innocentini Lopes de. Delimitação de uma área multidisciplinar para análise bibliométrica de produção científica: o caso da bioprospecção. Transinformação, Campinas, v.19, n.2, p.153-168, maio/ago. 2007.

MACIAS-CHAPULA, C. A. O papel da informetria e da cienciometria e sua perspectiva nacional e internacional. Ciência da Informação, Brasília, v.27, n.2, p. 134-40, maio/ago. 1998.

MEADOWS, A. J. A comunicação científica. Brasília: Briquet de Lemos, 1999.

MIRANDA, Antonio; BARRETO, Aldo de Albuquerque. Pesquisa em Ciência da Informação no Brasil: síntese e perspectiva. Revista de Biblioteconomia de Brasilia, v.23/24, n.3, p.277-92, 1999/2000. Número Especial.

MUGNAINI, Rogério; CARVALHO, Telma; CAMPANATTI-OSTIZ, Heliane. Indicadores de produçào científica: uma discussão conceitual. In: POBLACION, Dinah Aguiar; WITTER, Geraldina Porto; SILVA, José Fernando Modesto da. Comunicação \& produção científica: contexto, indicadores e avaliação. São Paulo: Angellara, 2006. p.313-340.

POBLACION, Dinah Aguiar; OLIVEIRA, Marlene de. Input e output: insumos para o desenvolvimento da pesquisa. In: POBLACION, Dinah Aguiar; WITTER, Geraldina Porto; SILVA, José Fernando Modesto da. Comunicação \& produção científica: contexto, indicadores e avaliação. São Paulo: Angellara, 2006. p. 57-80.

SANTOS, Raimundo Nonato Macedo dos. Produção científica: por que medir? O que medir? Revista Digital de Biblioteconomia e Ciência da Informação, Campinas, v.1, n.1, p.23-38, jul./dez. 2003. Disponível em: http://server01.bc.unicamp.br/seer/ojs. Acesso em: 11/04/2005.

SANZ CASADO, E. Los estudios métricos de la información y la evaluación del a actividad científica: conceptos básicos. [Material didático de curso "Os estudos métricos da informação", ministrado no Programa de Pós-Graduação em Ciência da Informação da ECA/USP, novembro 2006]

SENGUPTA, I. N. Bibliometrics, informetrics, scientometrics and librametrics: an overview. Libri, v. 42, n. 2, p. 99-135, 1992.

SPINAK, Ernesto. Indicadores cienciométricos. Ciência da Informação, Brasília, v.27, n.2, p.141-48, maio/ago. 1998. 
SZKLO, Moyses. Quality of scientifica articles. Revista de Saúde Pública, v.40, p.30-5, ago. 2006. Número especial.

TAGUE-SUTCLIFFE, J. Introduction to informetrics. Information Processing and Management, v. 28, n.1 p. 1-3, 1992.

TARGINO, Maria das Graças. Divulgação de resultados como expressão da função social do pesquisador. Revista de Biblioteconomia e Brasília, v.23/24, n.3, p.347-66, 1999/2000. Número Especial.

TARGINO, Maria das Graças; NEYRA, Osvaldo Nilo Balmaseda. Dinânica de apresentação de trabalhos em eventos científicos. Informação \& Sociedade: Estudos, João Pessoa, v.16, n.2, p.8-20, jul./dez. 2006.

\begin{abstract}
Concepts and basic considerations about metric studies of information, and the main methods and techniques, such as bibliometrics, scientometrics, informetrics, webmetrics, patentometrics and librametrics are presented. The scholarly communication cycle, specially the main input (resources) and output (product) indicators, as well as the importance of the publication of scientific research results and the peer review process are discussed. Some characteristics and applications of bibliometric laws, and the resources used for metrics studies of information are commented.
\end{abstract}

KEYWORDS: Bibliometric techniques. Scholarly communication. Bibliometric laws. Input indicators. Output indicators

Originais recebidos em: 08/02/2008

Texto aprovado em: 13/03/2008 